\title{
Analysis of Subsonic Incompressible Flow over a Rotating Disc
}

\author{
Ravi Kumar Shakya, Rishabh Bana, Priya Garg, S Rajkumar \\ Aerospace Engineer, SRM University, Chennai India
}

\begin{abstract}
Flows induced by rotating objects appear in turbo-machinery, storage devices of computers and ocean circulations, and the investigation of these flows is very interesting. An accurate and reliable analysis of the turbo machine rotating parts is of major concern to ensure fail proof and long life turbine engines. In the case of low aspect ratio of blades makes it necessary to treat them as plates. One of the typical cases of these phenomena is the flow which develops between a rotating disc and a stationary disc (shroud), and the flow has been investigated numerically and experimentally. In this work the basic flow field is investigated over a rotating disk with the shroud at the top. There is a small inlet for air in the shroud and the inlet air gains radial, circumferential and axial velocity due to the rotating disc. An analysis is made to obtain exact solutions for the flow of air due to a disk rotating with a constant angular speed. The studies have been pursued on 4 different revolutions per minute (rpm) and 3 different heights. The various rpm at which experiments were done are $500 \mathrm{rpm}, 600 \mathrm{rpm}, 700 \mathrm{rpm}$ and $800 \mathrm{rpm}$ and the various heights are $5 \mathrm{~cm}, 10 \mathrm{~cm}$ and $15 \mathrm{~cm}$.
\end{abstract}

Keywords: rotating disc, stationary disc, rpm and radial, circumferential and axial velocity.

\section{Introduction}

The flow around a rotating disc in a cylindrical enclosure was investigated numerically. The variance of the axial velocity component is a suitable as the measure of the asymmetry and the transition to the asymmetric state of the rotating flow. Taylor-Couette flow develops in the clearance between the disc rim and the shroud of the enclosure, and it makes the flow on stationary lids unstable. The effect of the flow in the clearance becomes larger as the gap width increases. When the rim-shroud clearance is small, basic flow, spiral rolls and turbulent spiral rolls, which were observed in system with no clearance, were predicted, while spiral rolls tend to cease at larger clearance.

\section{Experimental setup}

The experimental set-up consists of a DC Motor with controller, Aluminum Disc, shaft with flange, Ball bearing, coupling, Pitot static tube, Shroud made up of perplex sheet, Traverse Gear, Digital Manometer and stand for motor, shroud and bearing. The investigation for flows over rotating disk was performed as shown in Fig 1

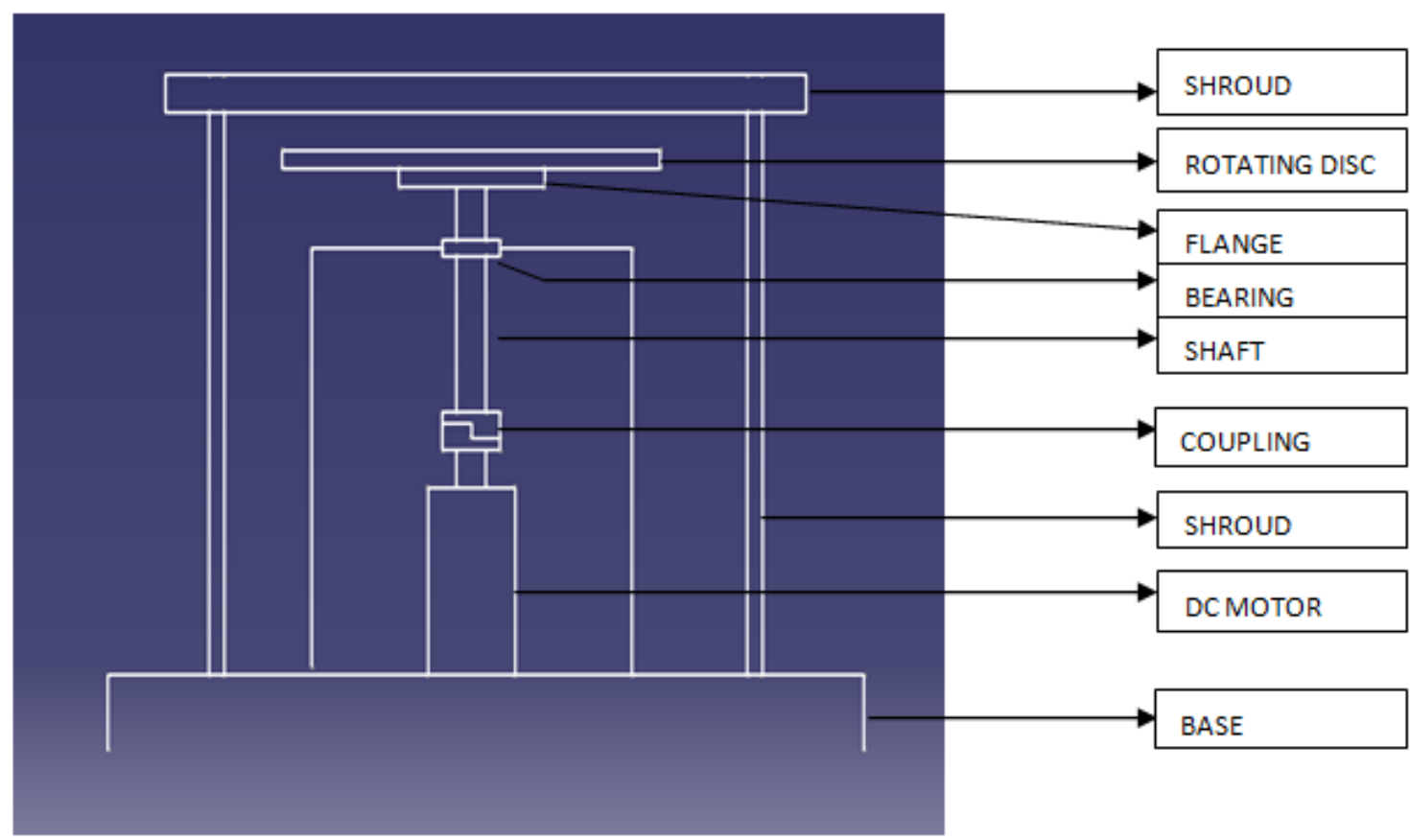

Figure: 1 
Here, DC Motor has $2.5 \mathrm{hp}$ (Power), max.5600 rpm and the controller for variable current varying from 0 to 6 Ampere (at constant voltage). Aluminum Disc has $50 \mathrm{~cm}$ diameter \& $5 \mathrm{~mm}$ thickness while Shroud has $70 \mathrm{~cm}$ diameter and $5 \mathrm{~mm}$ thickness, at the center of the shroud $2.5 \mathrm{~cm}$ diameter hole is made. Main Shaft is made up of mild steel and has diameter of $22 \mathrm{~mm}$. Mild Steel flange is used to connect aluminum disc and Main shaft .Coupling is used to connect motor shaft and Main shaft. Ball Bearing is used to reduce the friction between the Main Shaft and stand. Transverse Gear to hold and change the position pitot tube. Pitot tube is of $1 \mathrm{~m}$ length and is made up of copper; it is connected to Digital manometer through silicon plastic tubes. Four stands made and main stand collectively is used to hold perplex shroud and the main shaft respectively. RPM of the rotating aluminum disc is measured using digital tachometer.

\section{Experimentation Process}

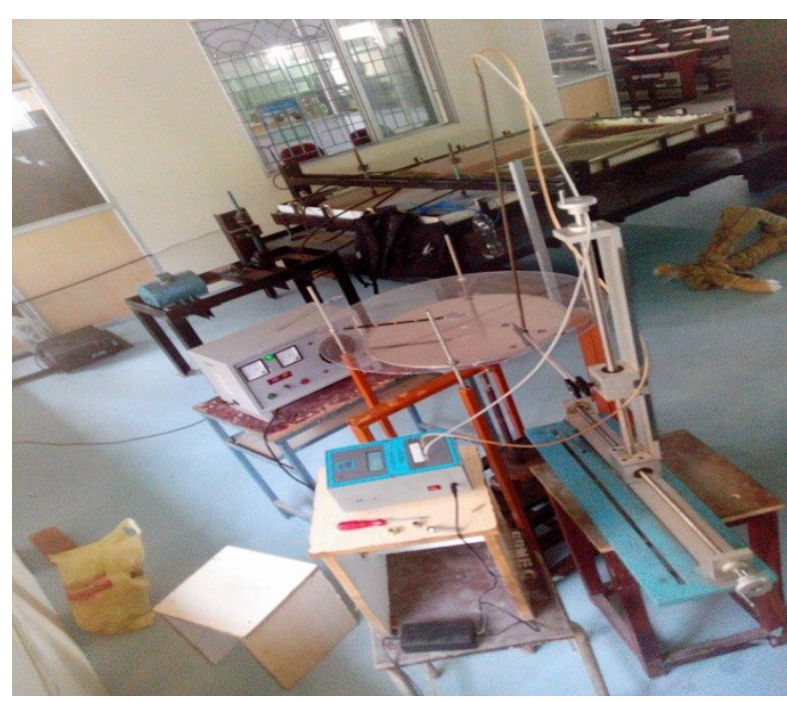

Figure: 2

The finished Aluminum disc is mounted on the flange using nut $\&$ bolts.

The DC Motor is connected to the controller and the voltage and current is set at zero.

Now the controller is switched $\mathrm{ON}$ and it is kept at initially $500 \mathrm{rpm}$. The distance between the shroud and disc is varied between 5 to $20 \mathrm{~cm}$ with an increment of $5 \mathrm{~cm}$. Initially the distance between the shroud and aluminum disc is kept $5 \mathrm{~cm}$ and the readings of static pressure and axial velocity of air is taken from the digital manometer.

Similarly, more readings are taken by varying the height of pitot static tube using Traverse Gear mechanism and also at four different RPM i.e. 500, 600, 700 and $800 \mathrm{rpm}$

\section{Calculation Procedure}

\section{Practical Calculations}

The pitot tube is connected to digital manometer and value of static pressure and velocity has been noted directly and rpm of disc is maintained by using tachometer. Stagnation pressure is calculated by adding static pressure and dynamic pressure.

$$
\begin{aligned}
& \text { Stagnation pressure }=\text { static pressure }+ \text { dynamic pressure } \\
& \qquad \mathrm{P}_{0}=\mathrm{P}_{\infty}+1 / 2 \rho \mathrm{V}_{\infty}^{2}
\end{aligned}
$$

Now The pitot tube is adjusted in such a way the we get radial and circumferential velocity at the same angle $\Theta$. By varying the height of the pitot tube, we get axial velocity and reading noted from manometer is the axial velocity reading. For calculating the radial and circumferential velocity, we have to take velocity just above the disk in sin and cos components.

$$
\begin{aligned}
& \text { Radial velocity }=\mathrm{V}_{\infty} * \cos \Theta \\
& \text { Circumferential velocity }=\mathrm{V}_{\infty} * \sin \Theta
\end{aligned}
$$

This procedure is repeated for all the four ports and for various heights. Then, shear stress and torque is calculated from radial and circumferential velocity.

Shear stress is calculated using formulae:

(Circumferential shear stress) $\mathrm{T}=\mu\left(\omega \mathrm{r}-\mathrm{v}_{1}\right) / \Delta$

(Radial shear stress) $\mathrm{T}=\mu * \Delta \mathrm{v}_{1} / \Delta \mathrm{h}$ 
Further, torque is calculated by:

$$
\text { Torque (Q) }=\int_{0}^{R} 2 \Pi r d r \cdot T \cdot r
$$

Like for Height $=5 \mathrm{~cm}$

For $\mathbf{r p m}=\mathbf{5 0 0}$

Radius of port $4, \mathrm{r}=20 \mathrm{~cm}$

Angular velocity $(\omega)=2 \Pi n / 60$

$\Delta \mathrm{h}=0.3 \mathrm{~cm}$

$=52.36 \mathrm{rad} / \mathrm{sec}$

From equation no. 2 ,

(Circumferential shear stress) $T_{\mathrm{c}}=5.5770 \times 10^{-3} \mathrm{~N} / \mathrm{m}^{2}$

From equation no. 3 ,

(Radial shear stress) $T_{\mathrm{r}}=0.5165 \times 10^{-3} \mathrm{~N} / \mathrm{m}^{2}$

From equation no. 4,

(Circumferential torque) $\mathrm{Q}_{\mathrm{c}}=0.182507 \times 10^{-3} \mathrm{~N}-\mathrm{m}$

(Radial torque) $\mathrm{Q}_{\mathrm{r}}=0.0169 \times 10^{-3} \mathrm{~N}-\mathrm{m}$

Total torque, $\mathrm{Q}=0.19931 \times 10^{-3} \mathrm{~N}-\mathrm{m}$

\section{Theoretical Calculation}

- First we have considered a constant rpm and calculate angular velocity $(\omega)$.

- From this angular velocity, we will calculate circumferential velocity over circular disk using the formulae: $v=\omega r$

- The distance between the disc and shroud is taken as dy.

- Then, Shear stress is calculated using formulae:

$$
\mathrm{T}=\mu \frac{d u}{d y}
$$

Where dynamic viscosity, $\mu=1.79 \times 10^{-5} \mathrm{~N} \mathrm{sec} / \mathrm{m}^{2}$

- Further, torque is calculated by:

$$
\text { Torque }(\mathrm{Q})=\int_{0}^{R} 2 \Pi r d r \cdot T \cdot r
$$

\section{Like For rpm $=\mathbf{5 0 0}$}

Angular velocity $(\omega)=2 \Pi n / 60$

Radius of the disc (r) $=0.25 \mathrm{~m}$

$$
=52.36 \mathrm{rad} / \mathrm{sec}
$$

Velocity $(\mathrm{v})=\omega * \mathrm{r}$

$$
=13.09 \mathrm{~m} / \mathrm{sec}
$$

From equation no. 5 ,

Shear stress $(\mathrm{T})=4.6862 \times 10^{-3} \mathrm{~N} / \mathrm{m}^{2}$

From equation no. 4 ,

Torque $(\mathrm{Q})=0.1534 \times 10^{-3} \mathrm{~N}-\mathrm{m}$

TABLE: for distance between disc and shroud $=5 \mathrm{~cm}$

PORT: $1 ; \mathrm{rpm}=500 ; \mathrm{h}=5 \mathrm{~cm}$

\begin{tabular}{|c|c|c|c|c|}
\hline S.No. & Distance (cm) & Velocity $(\mathbf{m m} / \mathbf{s e c})$ & Static Pressure(mm) & Stagnation Pressure(mm) \\
\hline 1 & 0 & 0 & 0 & 0 \\
\hline 2 & 0.2 & 540 & 0.4 & 178605.4 \\
\hline 3 & 0.4 & 590 & 0.4 & 213211.65 \\
\hline 4 & 0.6 & 610 & 0.39 & 227911.64 \\
\hline 5 & 0.8 & 650 & 0.31 & 258781.56 \\
\hline 6 & 1 & 690 & 0.27 & 291611.52 \\
\hline 7 & 1.2 & 720 & 0.22 & 317520.22 \\
\hline 8 & 1.4 & 810 & 0.17 & 401861.42 \\
\hline 9 & 1.6 & 840 & 0.14 & 432180.14 \\
\hline 10 & 1.8 & 850 & 0.11 & 442531.36 \\
\hline 11 & 2 & 870 & 0.08 & 463601.33 \\
\hline
\end{tabular}


Analysis Of Subsonic Incompressible Flow Over A Rotating Disc

\begin{tabular}{|c|c|c|c|c|}
\hline 12 & 2.2 & 900 & 0.05 & 496125.05 \\
\hline 13 & 2.4 & 930 & 0.02 & 529751.27 \\
\hline 14 & 2.6 & 960 & 0.01 & 564480.01 \\
\hline 15 & 2.8 & 980 & 0.01 & 588245.01 \\
\hline 16 & 3 & 970 & 0.03 & 576301.28 \\
\hline 17 & 3.2 & 960 & 0.06 & 564480.06 \\
\hline 18 & 3.4 & 900 & 0.09 & 496125.09 \\
\hline 19 & 3.6 & 860 & 0.11 & 453005.11 \\
\hline 20 & 3.8 & 820 & 0.15 & 411845.15 \\
\hline 21 & 4 & 790 & 0.17 & 382261.42 \\
\hline 22 & 4.2 & 740 & 0.19 & 335405.19 \\
\hline 23 & 4.4 & 690 & 0.22 & 291611.47 \\
\hline 24 & 4.6 & 670 & 0.25 & 274951.5 \\
\hline 25 & 4.8 & 600 & 0.27 & 220500.27 \\
\hline 26 & 5 & 0 & 0 & 0 \\
\hline
\end{tabular}

Now we compared the theoretical and Practical values of torque

\begin{tabular}{|l|l|l|l|}
\hline RPM $(\mathrm{r} / \mathrm{min})$ & $\begin{array}{l}\text { Theoretical Torque } \\
(\mathrm{N}-\mathrm{m})\end{array}$ & $\begin{array}{l}\text { Practical Torque for } \\
5 \mathrm{~cm}(\mathrm{~N}-\mathrm{m})\end{array}$ & $\begin{array}{l}\text { Practical Torque for } \\
10 \mathrm{~cm}(\mathrm{~N}-\mathrm{m})\end{array}$ \\
\hline 500 & $0.1534 \times 10^{-3}$ & $0.1993 \times 10^{-3}$ & $0.1495 \times 10^{-3}$ \\
\hline 600 & $0.184 \times 10^{-3}$ & $0.2393 \times 10^{-3}$ & $0.1798 \times 10^{-3}$ \\
\hline 700 & $0.2147 \times 10^{-3}$ & $0.2531 \times 10^{-3}$ & $0.2103 \times 10^{-3}$ \\
\hline 800 & $0.27537 \times 10^{-3}$ & $0.3216 \times 10^{-3}$ & $0.2396 \times 10^{-3}$ \\
\hline
\end{tabular}

\section{Graph Obtained}

\section{For Axial Velocity} shroud.

The distance of port 1 is $5 \mathrm{~cm}$, port 2 is $10 \mathrm{~cm}$, port 3 is $15 \mathrm{~cm}$ and port 4 is $20 \mathrm{~cm}$ from the centre of the

The graphs for axial velocity for four ports at $\mathrm{rpm}=500$

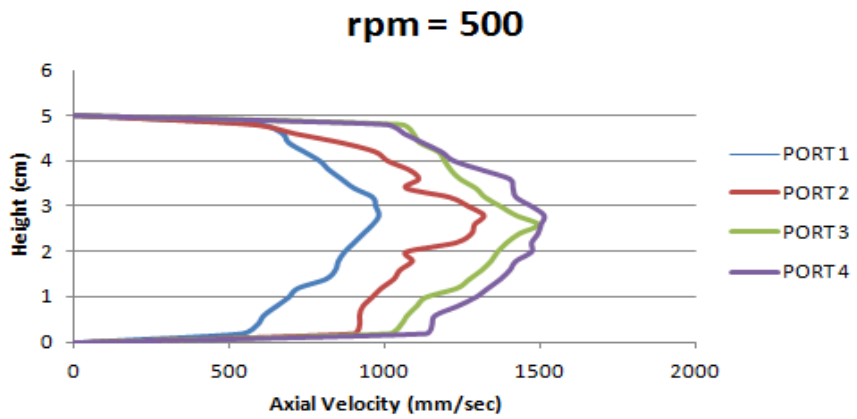

\section{For Circumferential Velocity}

rpm $=500$

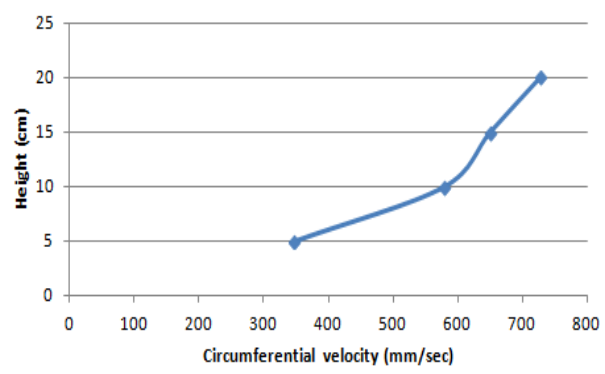

Figure: 3

\section{For Radial Velocity \\ rpm $=500$}

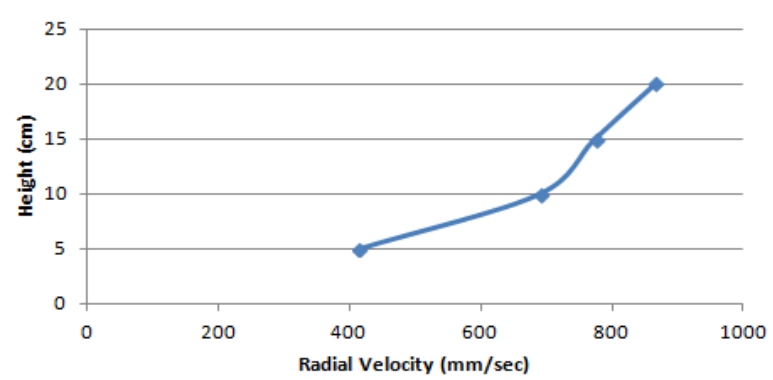

Figure: 4 


\section{Conclusion:}

The velocities which are experimentally determined can be verified by theoretical calculations. As we have compared the torque from experimental and theoretical calculations which come out to be same. The above graphs explained about the variation of axial velocity along height. As we know that the velocity should be zero at the shroud and aluminum surface, it is proved by the graphs above. The radial and circumferential velocity should increase as the radius of the disc increases and this can also be verified from previous results.

[1]. Fundamentals Of Aerodynamics by John D Anderson

\section{References:}

[2]. N. Aubry, M.-P. Chauve, R. Guyonnet, Transition to Turbulence on a Rotating Flat Disk, Phys.Fluids, 6, 2800-2814,1994.

[3]. Fluid Mechanics and Hydraulic Machines by R. K.Bansal

[4]. Experimental study of the rotating-disk boundary-layer own by Shintaro Imayama

[5]. Boundary-Layer Theory - Herrmann Schlichting

[6]. stability of flows over rough rotating disks by Joseph H. Harris and Peter J. Thomasy

University of Warwick, Coventry, Warwickshire, CV4 7AL, United Kingdom

Stephen J. Garrettz

University of Leicester, Leicester, Leicestershire, LE1 7RH, United Kingdom 